\title{
An Analytical Study of Flood Management in Bangladesh
}

\author{
Dr. Md. Mizanur Rahman, Md. Amirul Hossain, \\ Dr. Amartya Kumar Bhattacharya \\ Post-Doctoral Research Fellow, Nipissing University, 100 College Drive, Box 5002, North Bay, Ontario 18 \\ 8L7, CANADA. \\ Executive Engineer, Flood Forecasting and Warning Centre, Bangladesh Water Development Board, \\ WAPDA Building, Motijheel C/A, Dhaka - 1000, BANGLADESH. \\ Professor, Department of Applied Mechanics, Bengal Engineering and Science University, Shibpur Howrah- \\ 711103, West Bengal, INDIA.
}

\begin{abstract}
Bangladesh along with the state of West Bengal in India is situated in the lowest area of the Hindu Kush - Himalayan Region (HKH) and is famous as one of the highest flood prone countries in the world. Flood to some extent is an annual expected and well-come event for many reasons for this country. But extreme flood inundates more than half of the country's landmass causing immense suffering to the human life, damages properties and economy. Aim of the flood management in Bangladesh is to minimize damages or to avoid disastrous situation. Though the country is in the eastern part of the lowest ridge of HKH but geography and location of the country make hydrology of Bangladesh very diverse, complex and unique. The North-Eastern part of the country has the river networks with upper hilly catchments having one of the world's highest rainfall intensity and causes frequent flash floods. In the North-Western part rainfall intensity is lower, higher altitude and mighty perennial river network causes river flood. The South-Eastern part has moderate rainfall intensity, hilly as well as coastal plain land, flashy and tidal river network causes both the storm surge and flash flood. The South Western region has also moderate rainfall, coastal plain land and tidal rivers cause storm surge due to cyclone. Principles of flood management in the country based on these different types of floods and geographical conditions either by non-structural or structural measures. As a non-structural measure for flood loss minimization, flood forecasting and warning services has been emphasized. Structural measures began in late 60 's by implementing number of flood control projects.
\end{abstract}

\section{INTRODUCTION}

Bangladesh is located in the south-eastern part of Hindu Kush - Himalayan (HKH) region stretching between latitudes $20^{\circ} 34^{\prime} \mathrm{N}$ and $26^{\circ} 38^{\prime} \mathrm{N}$ and longitudes $88^{\circ} 01^{\prime} \mathrm{E}$ and $92^{\circ} 41^{\prime} \mathrm{E}$. The country contains the confluence of the Ganga, Brahmaputra, and Meghna Rivers and their tributaries, which are originate from the Himalayas ( except the Meghna ) and discharge into the Bay of Bengal. The terrain is mainly flat, and with $90 \%$ of its landmass upto 10 meters above mean sea level can be considered to be a primarily low lying riverine country. It is frequently hit by natural disasters, particularly floods, riverbank erosion, cyclones \& droughts. Each impacts on the livelihoods of those affected, but with different severity. Displacement due to flood and erosion and inadequate facilities during and after major floods, as shown in Fig. 1, can create major hardship and health problems.

The climate of Bangladesh is tropical monsoon climate influenced by the Himalayan Mountains in the north and northeast, and the Bay of Bengal in the south. High monsoon rains associated with Bangladesh's unique geographical location in the eastern part of the delta of the world's second largest river basin make it extremely vulnerable to recurring floods. Agriculture is the dominant land use in the country covering about $59 \%$ of the land, rivers and other water bodies constitute about 9\% (BBS, 2002). Monsoons with varying degrees of associated flooding are anticipated annual events in Bangladesh.

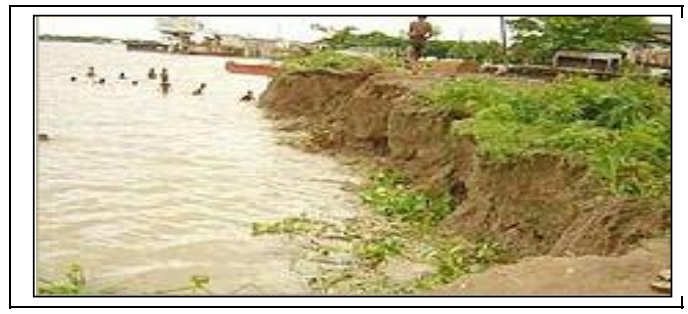

River Erosion due to Flood

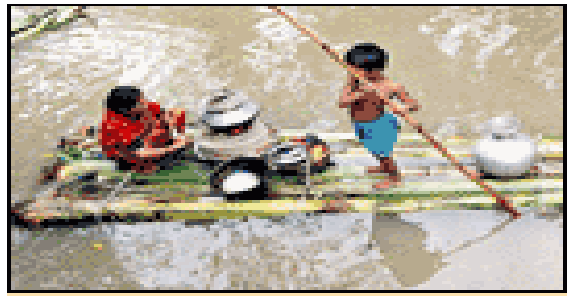

Lack of Flood Shelter facilities

Fig. 1: Erosion and inadequate facilities during and after major floods

(Source: The Daily Prothom Alo, 2004) 


\section{TYPES OF FLOODS IN BANGLADESH}

The term flood is generally used when the flows in the rivers and channel can not be contained within natural or artificial river banks. By spilling the river banks, when water inundates flood plains and adjoining high lands to some extent or when the water level in the river or channels exceeds certain stage, the situation then termed as flood (Hossain, 2004). In Bangladesh, the following types of floods are normally encountered. Area affected by different types of flooding is presented in Fig 2.

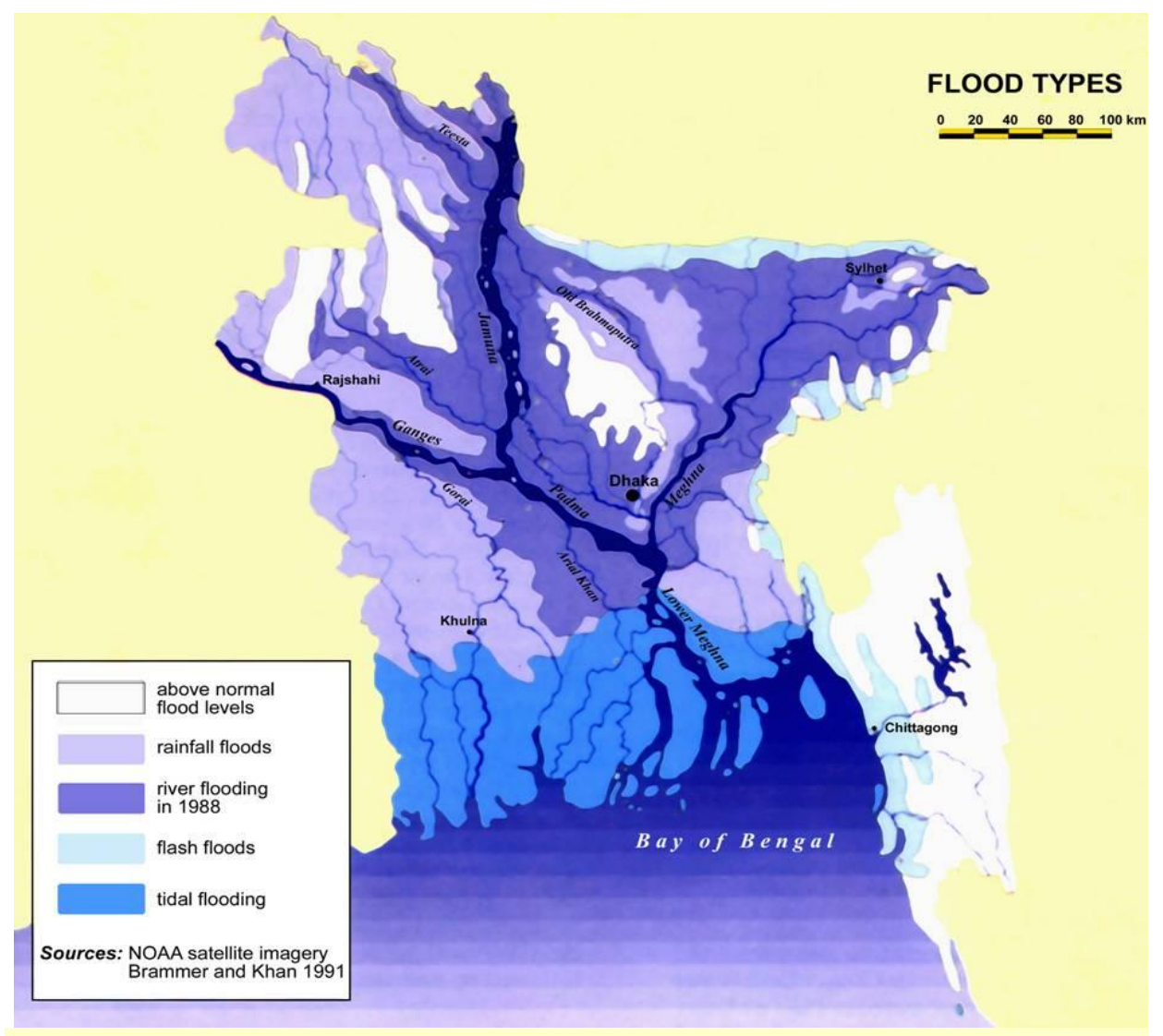

Fig. 2: Types of Flood in Bangladesh (Source: FFWC)

( Note : Rivers outside the boundaries of Bangladesh are not shown in the figure )

\section{Flash Flood from Hilly Areas}

Flash flood prone areas of the Bangladesh are at the foothills. Intense local and short-lived rainfall often associated with mesoscale convective clusters is the primary cause of flash floods. These are characterized by a sharp rise followed by a relatively rapid recession. Often with high velocities of on-rush flood damages crops, properties and fish stocks of the wetland. Flash flood can occur within a few hours. In the months of April and May flash floods affect the winter rice crop at the harvesting stage, and are common in the districts of Northeast and Southeast regions of the country.

\section{Monsoon Floods or Normal Flood from Major Rivers}

The word flood is generally synonymous with river flood. River flood is a common phenomenon in the country caused by bank overflow. Of the total flow, around $80 \%$ occurs in the 5 months of monsoon from June to October (WARPO, 2004). A similar pattern is observed in case of rainfall also. As a consequence to these skewed temporal distribution of river flow and rainfall, Bangladesh suffers from abundance of water in monsoon, frequently resulting into floods and water scarcity in other parts of the year, developing drought conditions (IEB, 1998). Climatologically, the discharge into Bangladesh, from upper catchments, occurs at different time of the monsoon. In the Brahmaputra maximum discharge occurs in early monsoon in June and July whereas in the Ganga maximum discharge occurs in August and September. Synchronisation of the peaks of these rivers results in devastating floods. Such incidents are not uncommon in Bangladesh. The rivers of 
Bangladesh drain about 1.72 million sq km area of which $93 \%$ lies outside its territory in India, Nepal, Bhutan and China. The annual average runoff of the cross boundary rivers is around 1200 cubic kilometres (WARPO, 2004).

\section{Rain-fed Flood}

This kind of flood generally occurs in many parts of the country but is mainly prevalent in the southwestern part of the country. This kind of flood also occurs in the flood plains where natural drainage systems have been disturbed either due to human interferences e.g. construction of unplanned rural roads and encroachment of river courses etc. or due to gradual decay of the natural drainage system. When intense rainfall takes place in those areas, the natural drainage system cannot carry the run-off generated by the storm and causes temporary inundation in many localities. This kind of rain-fed flood is increasing in the urban areas.

\section{Floods Due To Storm Surges}

This kind of flood mostly occurs along the coastal areas of Bangladesh over a coastline of about 800 $\mathrm{km}$ along the southern part. Continental shelves in this part of the Bay of Bengal are shallow and extend to about $20-50 \mathrm{~km}$. Moreover, the coastline in the eastern portion is conical and funnel like in shape. Because of these two factors, storm surges generated due to any cyclonic storm is comparatively high compared to the same kind of storm in several other parts of the world. In case of super-cyclones maximum height of the surges were found to be 10-15 m, which causes flooding in the entire coastal belt. The worst kind of such flooding was on 12 Nov 1970 and 29 April 1991 which caused loss of 300,000 and 138,000 human lives respectively (FFWC, 2005). Coastal areas are also subjected to tidal flooding during the months from June to September when the sea is in spate due to the southwest monsoon wind.

\section{GENERAL PATTERN}

The Brahmaputra starts rising in March due to snowmelt on the Himalayas, which causes a first peak in May or early June. It is followed by subsequent peaks up to the end of August caused by the heavy monsoon rains over the catchments. The response to rainfall is relatively quick, resulting in rapid increases of water level. The Ganga starts rising gradually in May-June to a maximum sometime in August. High water levels are normally sustained until mid September. The Meghna may not attain its annual peak until August-September. The upper Meghna carries only about $10 \%$ of the flow in the Ganga and Brahmaputra. The total volume of runoff in the GBM is determined by the net precipitation over all the catchments. The normal sequence of floods with flash floods in the eastern hill streams during the pre-monsoon period in the months of April and May. High floods occur if the peaks of the Ganga and Brahmaputra coincide; this may happen during AugustSeptember.

\section{FLOOD DAMAGES IN BANGLADESH}

Country has experienced seventeen highly damaging floods in the 20th century. Since independence in 1971, Bangladesh has experienced floods of a vast magnitude in 1974, 1984, 1987, 1988, 1998, 2000 \& 2004 (FFWC, 2005). The largest recorded flood in depth and duration of flooding in its history was occurred in 1998 when about $70 \%$ of the country was under water for several months (FFWC, 2005 \& Nishat et.al.-2000). Area affected in percent of the total area during major flood event inundating more than $20 \%$ of the country's land area of the country is presented in Fig. 2. Damages during some sever floods is presented in Table-1.

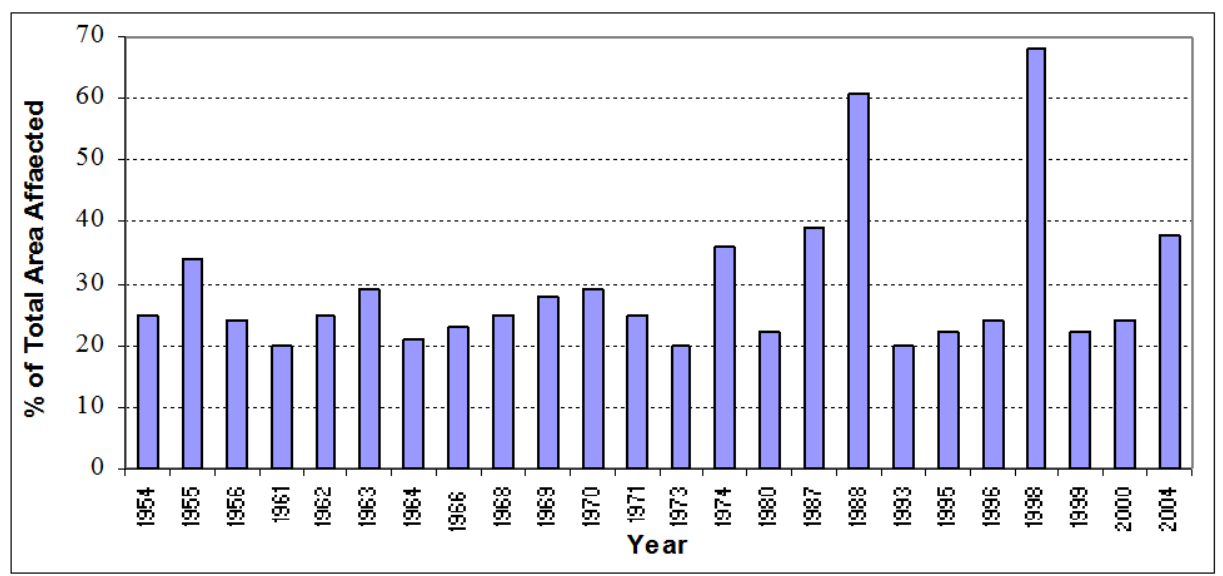

Fig. 2: Area affected in percent of the total area during major flood event 
Table-1: Some notable flood and cyclone induced storm surge events

\begin{tabular}{|l|l|}
\hline Event & Impact \\
\hline 1974 flood & $\begin{array}{l}\text { Inundated 36\% of the country (FFWC, 2005), estimated damages US\$ 57.9 Million, over } \\
28,700 \quad \text { deaths, (http://www.em-dat.net/disasters/Visualisation/profiles/natural-table- } \\
\text { emdat.php?country=Bangladesh dtd. 2.3.2006) }\end{array}$ \\
\hline 1987 flood & $\begin{array}{l}\text { Inundated over 57,000 sq-km area, estimated damage US\$ 1.0 billion and human death } \\
2055 \text { (The World Bank, 2002) }\end{array}$ \\
\hline 1988 flood & $\begin{array}{l}\text { Inundated 61\% of the country, persons affected } 45 \text { million, 2300 deaths, damage worth } \\
\text { about US\$ 1.2 billion (The World Bank, 2002) }\end{array}$ \\
\hline 2004 flood flood & $\begin{array}{l}\text { Inundated 100,250 sq-km (68\%) of the country, 1100 deaths, persons affected 31 million, } \\
\text { damaged 500,000 homes, 23,500 km roads and 4500 km embankment, destroyed crops of } \\
500,000 \text { ha of land, damage worth about US\$ 2.8 billion (The World Bank, 2002) }\end{array}$ \\
\hline $\begin{array}{l}\text { Inundated 38\% of the country, 750 deaths, persons affected 36 million, damaged 58,000 } \\
\text { km roads and 3,100 km embankment, crop damage 1.3 million ha, damage worth about } \\
\text { US\$ 2.2 billion (ADB-World Bank, 2004) }\end{array}$ \\
\hline
\end{tabular}

\section{FLOOD MANAGEMENT IN BANGLADESH}

Bangladesh tries to deal with flood and disaster with structural and non-structural measures. Systematic structural measures began by implementing flood control projects in sixties after the colossal flood of 1963 . Non-structural measures have introduced in seventies. Flooding is a natural phenomenon, which cannot be prevented. Complete flood control is not in the interests of most Bangladeshi farmers. The flood control measures and policies should be directed to mitigation of flood damage, rather than flood prevention. Resources should be allocated to help people adopt a life style that is conformable to their natural environment. Indigenous solutions such as changing the housing structures and crop patterns can help reduce flood damage. Moreover, good governance, appropriate environmental laws, acts and ordinances will be necessary to achieve sustainable economic development and to reduce any environmental degradation. In addition, implementation of an improved real-time flood and drought control warning system can reduce the damage caused by floods (http:// www.bytesforall.org/8th/control_flood.htm dtd 2.3.2006). In recent years, improved forecasting \& early warning system and preparedness measures have helped to reduce the number of lives lost by natural disasters.

\section{Flood Management by Structural Measures}

Structural option provided some benefits specially increase in agricultural production (BWDB, 2005 \& BBS, 2002) at earlier period but some adverse effects were observed later on (Nishat et. al., 2000). Notably, the construction of high embankment along the both banks of the rivers in some cases resulted in rise in bed levels due to siltation causing obstruction to drainage. In the coastal areas, although the construction of polders prevented salinity intrusion, but resulted in restriction of the movement of the tidal prism, sedimentation of tidal rivers and obstruction to the gravity drainage. Another important impact on agriculture was found that the farmers in most cases opted for production of cereal crops, especially HYV rice enjoying a flood free situation rather than going for crop diversification. Structural measure caused many adverse effects on the aquatic lives especially on open water fisheries.

National and regional highways and railways, to the extent feasible, have been raised above flood level. Raising feeder and rural roads will be determined in the context of disaster management plans.

River maintenance and erosion control : River maintenance through dredging are also going on in a limited case due to the high cost. Efforts are continued for erosion control on medium and small rivers.

Flood control and drainage project: Where possible Flood Control, Drainage and/or Irrigation (FCD/I) projects have been constructed. FCD/I project are of two types, namely (i) full flood control facilities; and (ii) partial flood control. Till date FCD/I projects provide facilities in about 5.38 million ha which is about $59 \%$ of the country's net cultivated land (BWDB, 2000-01). Flood control and drainage structures have also been provided in major cities to make the cities flood free.

\section{Flood Management by Non-Structural Measures}

Introduction of non-structural option i.e. Flood Forecasting and Warning System I Bangladesh started from early ' $70 \mathrm{~s}$ and contributed to the improvement of the capacity for flood preparedness and mitigation/minimization of flood losses. Other non-structural measures are discussed in the following.

Flood cum Cyclone Shelter: School buildings are so constructed that they can be used as flood-cum cyclone shelter especially in the coastal zone with highest risk of flood and storm surge. These structures are not intended to change the flood regime, and therefore, considered as no-structural measures of flood management. Flood proofing: Efforts have been made to provide vulnerable communities with mitigation by raising homesteads, schools and marketplaces in low-lying areas (rather than flood control) and in the char lands so that 
peasants can save their livestock and food stuff.

Concept of flood zoning and flood insurance are not practiced in the country till date. Flood zoning will facilitate development in a co-coordinated way to avoid expensive investments in vulnerable areas. Proper land development rules need to be developed based on the flood-zoning map.

Other non-structural measures practiced are:

- $\quad$ working with communities to improve disaster awareness.

- develop disaster management plans.

- relief and evacuation.

\section{Flood Forecasting and Warning}

Flood warning is concerned to reduce sufferings to human life and damages of economy and environment. Flood forecasting and Warning Service of Bangladesh was established in 1972 as a permanent entity under Bangladesh Water Development Board (BWDB). Initially co-axial correlation, gauge to gauge relationship and Muskingum-Cunge Routing Model were used for forecasting. From early nineties a numerical modelling based approach has been applied for flood forecasting and warning. Using the principal concept of mass transfer based on the continuity and momentum equations, dynamic computation has been used in this method. Very briefly, it comprises of estimating water levels using hydrodynamic simulation model (MIKE 11). Research on Modelling System and capacity building in the forecasting is currently emphasised. During the moha plabon (the severest flood) of the country in 1998, loss of lives and damage of FCD/I projects were minimum mainly because of flood forecasting and early warning (Islam and Dhar, 2000).

\section{DISASTER MITIGATION}

Disaster management (including disaster preparedness) involves prevention and mitigation measures, preparedness plans and related warning systems, emergency response measures and post-disaster reconstruction and rehabilitation. The main aims for water-related disaster management are to provide the means by which, through a combination of structural and non-structural measures and to the extent feasible and affordable, people are adequately warned of an approaching disaster, and are adequately supported in rebuilding their lives thereafter.

The Government of Bangladesh (GoB) established the Disaster Management Bureau (DMB) in 1993, which has prepared comprehensive Disaster Management Plans. DMB is working under the Ministry of Disaster Management and Relief. Standing orders on Disaster has been prepared in 1997 and upgraded in 1999 by the DMB (Chowdhury, 2003). At central level a National Disaster Management Council (NDMC) has formed headed by the Honourable Prime Minister including Ministers from different ministries as member. Inter Ministerial Disaster Management Co-ordination Council (IMDMCC) has also been formed which guided by the NDMC. Beside this, District, Thana and Union (lowest level of local government) level committees have also formed with the participation of local community for post-disaster management and mitigation. Task and responsibilities of each committee are stated in the standing order (MoDMR, 1997). By all these steps GoB has strengthen the disaster response capacity through institutional capacity building activities; community disaster response simulation drills; and stockpiling of essential relief items.

\section{LESSONS LEARNED}

Forecasting facilities, preparedness planning, during and post-disaster relief efforts have reduced the severity of flood disaster impacts. Non-Government Organizations (NGOs) have also responded in an important way. It has been observed that emergency flood fighting during peak flood, evacuation and relief operation can best be achieved with peoples' participation along with deployment of army. Proper maintenance of the existing FCD/I projects and embankment effectively eliminate flood disaster in the empoldered area. In 1988 only two major FCD/I projects were saved, on the other hand due to preventive and protective measures in 1998 only two projects were damaged even it had higher magnitude and longer duration.

\section{CONCLUSION}

Structural as well as non-structural measures are being emphasized for flood management in Bangladesh. It has been proved that non-structural measures have significant effect on flood damage minimization. Flood and disaster can not fully be controlled, prevented or eliminated, but damages can be reduced significantly by integration of measures and co-ordination of agencies. Flood forecasting and early warning is very important for a flood-prone country like Bangladesh. An effective and timely flood forecasting (Rahman, 2005) along with mitigation measures, both structural and non-structural, can save lives and properties, thus minimize the damages from disaster. The main data required for flood forecasting are river stage, river discharge, velocity, rainfall, humidity, geographical and vegetation information, river morphological (cross section) data etc. Co-operation is needed among regional government level as well as non-government 
level for research and development for improvement of flood mitigation measures.

\section{REFERENCES}

[1] Bangladesh Bureau of Statistics (BBS), 2002, Ministry of Planning, Bangladesh.

[2] Bangladesh Water Development Board, (BWDB), 2000-2001, Annual Report, Dhaka.

[3] Chowdhury, J.R., 2003, Technical Paper presented in the $47^{\text {th }}$ Annual Convention of the Institution of Engineers Bangladesh (IEB), 5-7 January, 2003, Chittagong.

[4] FFWC, 2005, Consolidation and strengthening of flood forecasting and warning services, Final Report, Volume II - Monitoring and evaluation, Bangladesh Water Develoment Board, Dhaka.

[5] Flood Forecasting and Warning Centre (FFWC), 2005, Annual Flood Report, BWDB, Dhaka.

[6] Hossain, A.N.H. Akhtar, 2004, Flood Management: Issues and Options. Presented in the International Conference organized by Institute of Engineers, Bangladesh.

[7] Islam, S.R., and Dhar, S.C., 2000, Bangladesh Floods Of 1998: Role Of Flood Forecasting \& Warning Centre, BWDB, Dhaka.

[8] Joint ADB-World Bank, 2004, Emergency Flood Damage Rehabilitation Project, Joint ADB-World Bank damage and need assessment, Dhaka, November.

[9] Nishat, A. et. al., 2000, The 1998 flood: Impact on Environment of Dhaka city, Ministry of Environment \& Forest and IUCN Bangladesh, Dhaka.

[10] Ministry of Disaster Management and Relief (MoDMR), 1997, Standing Order for Disaster Management, Dhaka.

[11] Rahman, M. M., 2005, Geo-informatics approach for augmentation of lead time of flood forecastingBangladesh Perspective, Proceedings of International Conference on Hydrological Perspectives for Sustainable Development in Department of Hydrology, Indian Institute of Technology, Roorkee, Uttaranchal, India, Feb 23-25.

[12] The Institution of Engineers Bangladesh (IEB), 1998, Report of the task force committee on flood management, Dhaka.

[13] The World Bank, 2002, Bangladesh Disaster \& Public Finance, Paper no-6, Dhaka.

[14] Water Resources Planning Organization (WARPO), 2004, National Water Management Plan (NWMP),Ministry of Water Resources, Bangladesh, Dhaka. 